\title{
HapMap-based study of CIP2A gene polymorphisms and HCC susceptibility
}

\author{
YUCHUN LI ${ }^{1,2}$, KAIJUAN WANG ${ }^{1,2}$, LIPING DAI ${ }^{1,2}$, PENG WANG $^{1,2}$, CHUNHUA SONG $^{1,2}$, \\ JIANXIANG SHI $^{1,2}$, PENGFEI REN ${ }^{1,2}$, HUA YE $^{1,2}$ and JIANYING ZHANG ${ }^{1-3}$ \\ ${ }^{1}$ Department of Epidemiology, College of Public Health, Zhengzhou University, Zhengzhou 450001; \\ ${ }^{2}$ Henan Key Laboratory of Tumor Epidemiology, Zhengzhou University, Zhengzhou, Henan 450052, P.R. China; \\ ${ }^{3}$ Department of Biological Sciences, University of Texas, El Paso, TX 79968, USA
}

Received January 15, 2012; Accepted May 15, 2012

DOI: $10.3892 / \mathrm{ol} .2012 .728$

\begin{abstract}
CIP2A is a human oncoprotein that inhibits PP2A and stabilizes c-myc in human malignancies. Autoantibodies to CIP2A protein have been reported to be present in higher levels in sera from patients with hepatocellular carcinoma (HCC) than in sera of healthy individuals. The CIP2A gene has been demonstrated as a potential cancer susceptibility gene. To elucidate whether common CIP2A variants are associated with HCC susceptibility, we conducted a case-control study comprising 233 cases of HCC and 280 controls matched on age, gender and ethnicity in the Chinese Han population. Two haplotype-tagging single nucleotide polymorphisms (htSNPs) (rs2278911 and rs4855656) from the HapMap database were analyzed, which provide an almost complete coverage of the genetic variations in the CIP2A gene. We found that neither of these htSNPs and haplotypes were associated with the risk of HCC. However, an interaction was observed between hepatitis virus B and C infection (HBV and $\mathrm{HCV}$ ) and the $\mathrm{C}$ carriers (TC or CC) of $r s 2278911$ on HCC risk $(\mathrm{OR}=12.35 ; 95 \% \mathrm{CI}, 4.93-19.87)$. No such association was found for $r s 4855656$. Our study also demonstrated that two htSNPs ( $r s 2278911$ and $r s 4855656)$ in the CIP2A gene are not associated with the risk of HCC. HBV and HCV infection was found to exert a synergistic effect on the risk of HCC in individuals with the C carriers (TC or CC) of $r s 2278911$ in the Chinese Han population.
\end{abstract}

\section{Introduction}

Hepatocellular carcinoma (HCC), or liver cancer, is the fifth most common type of cancer and the third leading cause of cancer-related mortality worldwide (1). At least two-thirds

Correspondence to: Dr Jianying Zhang, Department of Epidemiology, College of Public Health, Zhengzhou University, 100 Science Ave, Zhengzhou 450001, P.R. China

E-mail: jianyingzhang@hotmail.com

Key words: HapMap, CIP2A, polymorphism, hepatocellular carcinoma of the 650,000 cases of HCC reported globally each year are found in Asian countries (2). China is estimated to have the highest incidence of HCC (34.1 for males and 13.7 for females, per 100,000 world standard population as of 2008), accounting for $53.5 \%$ (approximately 401,000 cases) of newly diagnosed cases in the world (approximately 749,000 cases) in 2008 (3). Chronic infections of hepatitis B virus (HBV) and hepatitis $\mathrm{C}$ virus (HCV), excessive alcohol consumption, tobacco smoking, aflatoxin B1 (AFB1) and diabetes are reported to be associated with an increased risk of HCC (4-10). Among these known or suspected risk factors, single nucleotide polymorphisms (SNPs) may also play a significant role in infectious and non-infectious pathways associated with HCC (11-14). SNPs of oncogenes and anti-oncogenes may alter the gene expression level and are functionally associated with $\mathrm{HCC}$ and other forms of liver disease (15).

The common disease-common variant (CD-CV) hypothesis holds that the genetic risk factors that contribute the most to the risk of disease are likely to be commonly occurring polymorphisms (16). Linkage disequilibrium (LD) mapping appears to be a reasonable approach to narrow down the number of potential risk genes or variants for the disease (17). The International HapMap Project $(18,19)$ (www.hapmap.org) provides a systematic framework of LD and haplotype structure for common SNPs. Haplotype-tagging single nucleotide polymorphisms (htSNPs) can be selected from the International HapMap database for genome-wide association studies (20). The htSNPs act as a minimal set of highly informative SNP markers that capture $95 \%$ of the common haplotype diversity of the genome.

CIP2A, also termed p90, was originally identified by Soo Hoo et al (21). Findings of our previous studies suggested that p90 was a novel cytoplasmic cancer autoantigen, and demonstrated that autoantibodies to $\mathrm{p} 90$ protein were found in $21 \%$ of HCC patients $(21,22)$. The function of p90 remained unknown until 2007 when Junttila et al (23) reported that p90 possessed oncogenic activity by inhibiting the tumor suppressor protein phosphatase 2A (PP2A) and stabilizing c-myc in human malignancies. These authors proposed renaming $\mathrm{p} 90$ to cancerous inhibitor of PP2A (CIP2A). Their results suggested that CIP2A may be an endogenous interaction partner for the PP2A complex. Moreover, the data showed that amino acids 
between 461 and 533 on CIP2A appeared to be necessary for the interaction. However, the association of CIP2A variants and HCC susceptibility has not been investigated. The aim of our study was to test the association of CIP2A gene polymorphisms and HCC susceptibility using the HapMap database in the Chinese Han population. We attempted to identify sufficient SNPs to tag all the common haplotypes across a $39.776 \mathrm{~kb}$ region encompassing the CIP2A gene.

\section{Materials and methods}

Clinical data. This hospital-based case-control study comprised $233 \mathrm{HCC}$ cases and 280 cancer-free controls. From September 2009 to December 2010, cases were consecutively selected and enrolled from patients in the Department of General Surgery, the Department of Oncology and the Department of Hepatology and Infectious Diseases at the First Affiliated Hospital of Zhengzhou University, China. All cases were diagnosed as primary HCC and had not received previous treatment of chemotherapy or radiotherapy. Controls were randomly selected from patients who attended the same hospital for an annual physical examination. In the control group, cancer-free status was ensured following detailed questioning by doctors. Randomly selected controls were matched with the HCC patients on age ( \pm 5 years), gender and ethnicity. None of the subjects had any biological relationship with each other. The covariate data were obtained from questionnaires which included the following aspects: a) demographic data including age and gender; b) smoking and drinking history; and c) family history of liver cancer. Stratified analysis was performed according to the drinking and smoking history (Table I). The hepatitis B surface antigen (HBsAg) or antibodies to hepatitis $\mathrm{C}$ virus (anti-HCV) detection data were obtained by clinical examination. Study protocols were approved by the ethics committee of Zhengzhou University and all participants provided written informed consent.

Definition of smoking history and alcohol drinking. Smoking history was categorized into four levels: never (non-smoker or $<1$ pack/year), low (<20 packs/year), moderate (20-40 packs/ year) and high ( $\geq 40$ packs/year). Drinking history was categorized into three levels: never (non-drinker or $<1$ drink per day), $0-2$ alcoholic drinks per day and $>2$ alcoholic drinks per day. Following the criteria defined by the National Institute on Alcohol Abuse and Alcoholism in the United States, one standard drink of alcohol was defined as any alcoholic beverage containing $14 \mathrm{~g}$ of pure alcohol.

SNP selection. HtSNPs from the HapMap database (http:// www.hapmap.org, HapMap Data Rel 27 Phase II+III, Feb09, on NCBI B36 assembly, dbSNP b126) were selected using tagger pairwise selection approaches using TagSNPs software online, with an $\mathrm{r}^{2}$ cutoff of 0.8 and a minor allele frequency cutoff of 0.05 in the database of Han Chinese in Beijing. HapMap data on 11 SNPs revealed that two htSNPs tagged two common haplotypes that spanned the CIP2A region: $r s 2278911$ (exon $6 \mathrm{C} / \mathrm{T}$ ), and $r s 4855656$ (intron 2 G/A). rs2278911 demonstrated a CGA-to-CAA mutation in codon 229, leading to the amino acid substitution of an Arginine for a Glutamine.
Genotyping. The DNA isolation kit (Dingguo Biotechnology Co., Ltd., Beijing, China) was used to extract the genomic DNA from $1 \mathrm{ml}$ peripheral blood sample. The $r s 2278911$ genotypes of all subjects were detected using the polymerase chain reaction-restriction fragment length polymorphism (PCR-RFLP) method. Primers were designed and synthesized by Beijing SBS Genetech Co., Ltd. The sequences were as follows: $r s 2278911,5$ '-CCA TCA CCG TTT ATG AGA AT-3' (forward) and 5'-CTT GTT GGC CCA TAG TAG TT-3' (reverse). A thermocycler was used to perform PCR on rs 2278911 , as follows: $95^{\circ} \mathrm{C}$ for $5 \mathrm{~min}, 35$ cycles of $95^{\circ} \mathrm{C}$ for $30 \mathrm{sec}, 54^{\circ} \mathrm{C}$ for $40 \mathrm{sec}, 72^{\circ} \mathrm{C}$ for $45 \mathrm{sec}$ and extension at $72^{\circ} \mathrm{C}$ for $10 \mathrm{~min}$. The PCR products were then digested by restriction enzyme TaqI (Takara Biotechnology Co., Ltd.) at $65^{\circ} \mathrm{C}$ overnight. The digested products were subsequently separated using $2 \%$ agarose gel electrophoresis, stained with ethidium bromide and visualized under ultraviolet light. Three different patterns of bands were observed: a single band 295 bp in length indicated the TT genotype in which the PCR products of $r s 2278911$ were not digested; three bands of 295, 241 and $54 \mathrm{bp}$ indicated the TC genotype in which the products were only partially digested; and two bands of 241 and 54 bp indicated the CC genotype in which the products were completely digested (Fig. 1). Negative controls (no template controls) and controls of known genotypes were included in the assay. Repeated genotyping of $20 \%$ randomly selected samples yielded identical results.

Genotyping of CIP2A rs4855656 was performed using allele-specific PCR (AS-PCR). AS-PCR is a simple, rapid and reliable method for detecting any mutation involving a single base change or small deletions. Based on the SNPs in the genome, the AS-PCR primers were designed with specific mismatches at the $3^{\prime}$ end that allowed preferential amplification of one allele relative to another on account of the primers being complementary to the SNP site (24). Additional deliberate mismatches should normally be introduced at the penultimate base of the AS-PCR primer to increase the specificity of the AS-PCR reaction. Since different mismatches have been found to have different destabilizing effects, it was necessary to consider both terminal and penultimate mismatches together. If the mutation-induced terminal mismatch was strong, a weak additional mismatch should be selected, and vice versa (25). Primers were designed and synthesized by Beijing SBS Genetech Co., Ltd. The sequences were as follows: rs 4855656: 5'-GA AGA GTT TTA TGT AAA CCC CGT A-3' (forward for A allele), 5'-A AGA GTT TTA TGT AAA CCC CGT G-3' (forward for G allele) and 5'-TGA ATT AGC ATA GGC TCC AGA A-3' (common reverse primer). Then, each DNA sample was run in two separate reactions, one for each allele. One tube (one tube = one reaction) contained the forward primer for the A allele and the reverse primer, and the other contained the forward primer for the $G$ allele and the reverse primer. PCR was performed as follows: $95^{\circ} \mathrm{C}$ for $5 \mathrm{~min}, 35$ cycles of $95^{\circ} \mathrm{C}(30 \mathrm{sec}), 53^{\circ} \mathrm{C}$ (forward primer for $\mathrm{A}$ allele and the reverse primer) and $52^{\circ} \mathrm{C}$ (forward primer for $\mathrm{G}$ allele and the reverse primer) $(40 \mathrm{sec}), 72^{\circ} \mathrm{C}(40 \mathrm{sec})$ and extension at $72^{\circ} \mathrm{C}$ for $10 \mathrm{~min}$. The SNPs were detected according to the presence and absence of the PCR products on $1 \%$ agarose gel. The product was 514 bp in length (Fig. 2). The sequencing of certain randomly selected samples was 


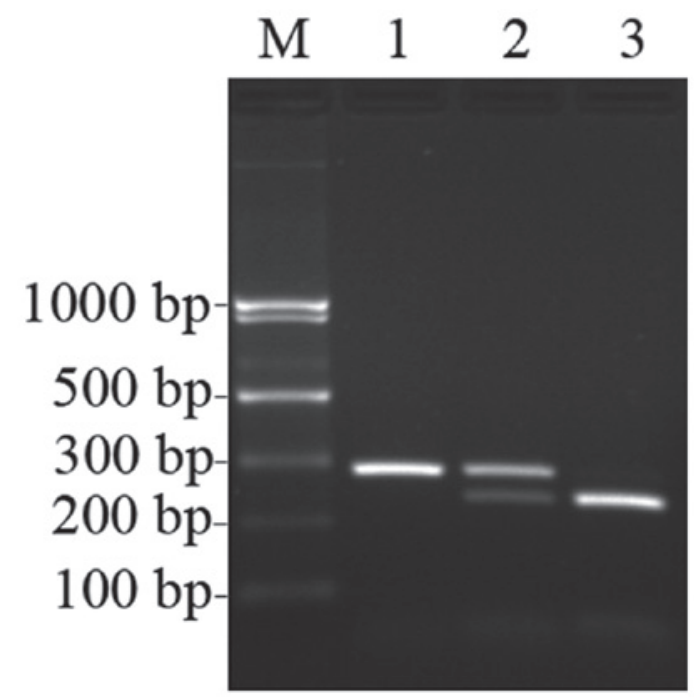

Figure 1. Three genotypes were found to exist in rs 2278911 following digestion with the restriction enzyme TaqI. M, marker; Lane 1, a single band of 295 bp that represented the TT genotype; lane 2, three bands of 295, 241 and 54 bp that represented the TC genotype; lane 3, two bands of 241 and $54 \mathrm{bp}$ that represented the $\mathrm{CC}$ genotype.

performed and identical genotypes were obtained. Overall, the genotyping success rate was $100 \%$.

Statistical analysis. The Hardy-Weinberg equilibrium equation was used to determine whether the proportion of each genotype obtained was in agreement with the expected values as calculated from the allele frequencies. The Chi-square test was used to examine the differences in demographic variables. The Student's t-test was used to compare the mean ages of cases and controls. Unconditional logistic regression analysis was used to estimate the odds ratio (OR) and its $95 \%$ confidence interval (CI) as a measure of the association between the different genotypes and the risk of HCC. SNPHAP software was used to analyze the haplotypes of $r s 2278911$ and $r s 485565$. We examined the potential interaction effects between different genotypes of the two htSNPs and other risk factors on HCC risk. To assess whether the combined effect of two factors on HCC was greater than the individual effects, we used the method described by Rothman (26). Under the null hypothesis of additivity, the synergy index (S) proposed by Rothman would take on the value 1 . The $\mathrm{P}$-value of $\mathrm{S}$, which is $<0.05$, is indicative of a statistically significant synergistic effect between the two factors.

$\mathrm{P}$-values were two sided and $\mathrm{P}<0.05$ was considered to indicate a statistically significant result. Data analysis was performed using Statistical Product and Service Solutions software (version 15.0, SPSS, Inc., Chicago, IL, USA) unless otherwise specified.

\section{Results}

Demographic characteristics. The distribution of demographic characteristics among the cases and controls is shown in Table I. The mean age of the HCC patients was $54.9 \pm 12.65$ years [mean \pm standard deviation (SD)] and that of

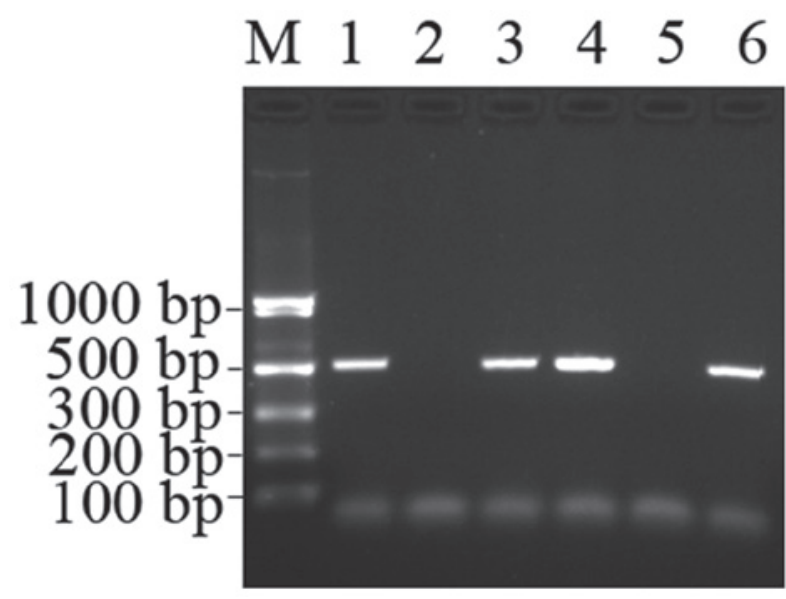

Figure 2. Three genotypes were found to exist in rs4855656. M, marker; Lanes 1, presence and 2, absence represented the AA genotype; lanes 3, presence and 4, presence represented the AG genotype; lanes 5, absence and 6 , presence represented the GG genotype.

the controls was $54.9 \pm 12.67$ years (mean $\pm \mathrm{SD}, \mathrm{P}=0.79$ ), indicating that there was no difference between the two groups. Males comprised $67.0 \%$ of the HCC cases and $64.6 \%$ of the control group $(\mathrm{P}=0.67)$. Compared with alcohol non-drinkers, subjects who drank 0-2 standard drinks of alcohol per day had an OR value of 1.98 (95\% CI, 1.09-3.76), while subjects who drank more than 2 standard drinks of alcohol per day had an OR value of 1.83 (95\% CI, 1.16-2.95). The OR value was found to rise with the increase of the alcohol dose $\left(P_{\text {trend }}<0.01\right)$. Similarly, a clear association was observed between smoking history and the risk of HCC. Taking non-smokers as a reference, subjects who smoked more than 40 packs per year had an OR value of 2.18 (95\% CI, 1.41-3.23). The OR value was elevated with the increase of the smoking dose $\left(P_{\text {trend }}<0.01\right)$. Chronic HBV and HCV infection markers, HBsAg+ and anti$\mathrm{HCV}+$ were more prevalent among $\mathrm{HCC}$ cases than controls, with an OR value of 8.34 (95\% CI, 4.54-12.97). Family history of HCC was also associated with $\mathrm{HCC}$, with an OR value of 3.35 (95\% CI, 1.98-5.76).

Genotype frequencies and HCC risk. The distribution of genotype frequencies of CIP2A polymorphisms in HCC cases and controls is shown in Table II. The genotype distribution of $r s 2278911$ and $r s 4855656$ in the cases and controls did not deviate from the expected Hardy-Weinberg equilibrium ( $r s 2278911, \mathrm{P}=0.22 ; r s 4855656, \mathrm{P}=0.89$ ). No differences were found in the genotype frequencies in either of the SNPs between the case group and control group. Compared with the TT genotype of $r s 2278911$, no obvious association was found between the TC or CC genotype and the risk of HCC (TC genotype: $\mathrm{OR}=1.08$; 95\% CI, 0.64-1.59; CC genotype: $\mathrm{OR}=0.98 ; 95 \% \mathrm{CI}$, 0.42-1.73). Compared with the GG homozygous genotype of $r s 4855656$, GA and AA genotypes showed no statistical difference between the two groups (GA genotype: $\mathrm{OR}=0.64 ; 95 \%$ CI, 0.32-1.04; AA genotype: $\mathrm{OR}=1.68$; 95\% CI, 0.94-2.83).

Haplotype analysis. As shown in Table III, there were four possible haplotypes in total and no significant difference was found in the distribution of haplotypes between the cases and 
Table I. Selected characteristics distribution in cases and controls.

\begin{tabular}{|c|c|c|c|c|}
\hline Variables & Cases, N (\%) & Controls, N (\%) & OR $(95 \% \mathrm{CI})^{\mathrm{a}}$ & P-value \\
\hline Mean age (SD) & $54.9(12.65)$ & $54.9(12.67)$ & & 0.79 \\
\hline \multicolumn{5}{|l|}{ Gender $(\%)$} \\
\hline Male & $156(67.0)$ & $181(64.6)$ & & 0.67 \\
\hline Female & $77(33.0)$ & $99(35.4)$ & & \\
\hline \multicolumn{5}{|l|}{ Alcohol drinking per day } \\
\hline Never & $151(64.8)$ & $216(77.1)$ & Ref & \\
\hline Ever & $82(35.2)$ & $64(22.9)$ & $1.85(1.21-2.76)$ & $<0.01^{b}$ \\
\hline \multicolumn{5}{|l|}{ Drinks per day } \\
\hline None & $151(64.8)$ & $216(77.1)$ & Ref & \\
\hline $0-2$ & $26(11.2)$ & $19(6.8)$ & $1.98(1.09-3.76)$ & $0.03^{\mathrm{b}}$ \\
\hline$>2$ & $56(24.0)$ & $45(16.1)$ & $1.83(1.16-2.95)$ & $0.01^{\mathrm{b}}$ \\
\hline$P_{\text {trend }}$ & & & & $<0.01^{b}$ \\
\hline \multicolumn{5}{|l|}{ Smoking history } \\
\hline Never & $123(52.8)$ & $179(63.9)$ & Ref & \\
\hline Ever & $110(47.2)$ & $101(36.1)$ & $1.64(1.23-2.39)$ & $0.01^{\mathrm{b}}$ \\
\hline \multicolumn{5}{|l|}{ Packs per year } \\
\hline None & $123(52.8)$ & $179(63.9)$ & Ref & \\
\hline$<20$ & $12(5.2)$ & $26(9.3)$ & $0.69(0.35-1.42)$ & 0.28 \\
\hline $20-40$ & $25(10.7)$ & $24(8.6)$ & $0.66(0.48-1.37)$ & 0.18 \\
\hline$\geq 40$ & $73(31.3)$ & $51(18.2)$ & $2.18(1.41-3.23)$ & $<0.01^{\mathrm{b}}$ \\
\hline$P_{\text {trend }}$ & & & & $<0.01^{\mathrm{b}}$ \\
\hline \multicolumn{5}{|l|}{$\mathrm{HBV} / \mathrm{HCV}$ infection } \\
\hline HBsAg-/Anti-HCV- & $115(49.4)$ & $249(88.9)$ & Ref & \\
\hline HBsAg+/Anti-HCV+ & $118(50.6)$ & $31(11.1)$ & $8.34(4.54-12.97)$ & $<0.01^{b}$ \\
\hline \multicolumn{5}{|l|}{ Family history } \\
\hline Yes & $49(21.0)$ & $21(7.5)$ & Ref & \\
\hline No & $184(79.0)$ & $259(92.5)$ & $3.35(1.98-5.76)$ & $<0.01^{b}$ \\
\hline
\end{tabular}

${ }^{\mathrm{a}}$ Adjusted for age, gender, alcohol drinking, smoking history, HBsAg or anti-HCV and family history. ${ }^{\mathrm{b}}$ Different between cases and controls $(\mathrm{P}<0.05)$.

Table II. Frequencies of genotypes for two htSNPs of CIP2A and the risk of HCC.

\begin{tabular}{|c|c|c|c|}
\hline Locus genotype & Cases, N (\%) & Controls, N (\%) & OR $(95 \% \mathrm{CI})^{\mathrm{a}}$ \\
\hline \multicolumn{4}{|l|}{$r s 2278911$} \\
\hline $\mathrm{TT}$ & $78(33.5)$ & $101(36.1)$ & Ref \\
\hline $\mathrm{TC}$ & $117(50.2)$ & $126(45.0)$ & $1.08(0.64-1.59)$ \\
\hline $\mathrm{CC}$ & $38(16.3)$ & 53 (18.9) & $0.98(0.42-1.73)$ \\
\hline C carriers & $155(66.5)$ & $179(63.9)$ & $1.56(0.98-2.12)$ \\
\hline \multicolumn{4}{|l|}{$r s 4855656$} \\
\hline GG & $134(57.5)$ & $152(54.3)$ & Ref \\
\hline GA & $75(32.2)$ & 108 (38.6) & $0.64(0.32-1.04)$ \\
\hline AA & $24(10.3)$ & $20(7.1)$ & $1.68(0.94-2.83)$ \\
\hline A carriers & $99(42.5)$ & $128(45.7)$ & $1.19(0.85-1.94)$ \\
\hline
\end{tabular}

${ }^{a}$ Adjusted for age, gender, alcohol drinking, smoking history, HBsAg or anti-HCV and family history. 
Table III. rs2278911 and rs4855656 haplotype analysis using SNPHAP software.

\begin{tabular}{lcccccr}
\hline Haplotype & Structure & Cases, N $(\%)$ & Controls, N $(\%)$ & Total (\%) & OR (95\% CI) & P-value \\
\hline Hap1 & TG & $269(57.7)$ & $322(57.5)$ & $591(57.6)$ & 1.0 & \\
Hap2 & CA & $117(25.1)$ & $144(25.7)$ & $261(25.4)$ & $0.97(0.73-1.30)$ & 0.85 \\
Hap3 & CG & $76(16.3)$ & $90(16.1)$ & $166(16.2)$ & $1.01(0.72-1.43)$ & 0.95 \\
Hap4 & TA & $4(0.9)$ & $4(0.7)$ & $8(0.8)$ & $1.20(0.30-4.83)$ & 0.80 \\
Total $(\%)$ & & $466(100.0)$ & $560(100.0)$ & $1,026(100.0)$ & & \\
\hline
\end{tabular}

Table IV. Interactions between rs2278911 genotypes and other risk factors.

\begin{tabular}{|c|c|c|c|c|c|c|}
\hline Risk factors & Genotype & $\begin{array}{l}\text { Cases } \\
\mathrm{N}(\%)\end{array}$ & $\begin{array}{l}\text { Controls } \\
\mathrm{N}(\%)\end{array}$ & OR $(95 \% \mathrm{CI})^{\mathrm{a}}$ & $\begin{array}{c}\text { Synergy } \\
\operatorname{index}^{\mathrm{b}}(\mathrm{S})\end{array}$ & P-value \\
\hline Alcohol drinking & $r s 2278911$ & & & & & \\
\hline Never & TT & $60(25.8)$ & $85(30.4)$ & Ref & & \\
\hline Never & $\mathrm{TC}$ or $\mathrm{CC}$ & $91(39.1)$ & $131(46.8)$ & $0.96(0.62-1.50)$ & & \\
\hline Ever & TT & $18(7.7)$ & $16(5.7)$ & $1.57(0.75-3.39)$ & & \\
\hline Ever & $\mathrm{TC}$ or $\mathrm{CC}$ & $64(27.5)$ & $48(17.1)$ & $1.92(1.17-3.12)$ & 1.74 & 0.34 \\
\hline Smoking history & $r s 2278911$ & & & & & \\
\hline Never & TT & $42(18.0)$ & $68(24.3)$ & Ref & & \\
\hline Never & $\mathrm{TC}$ or $\mathrm{CC}$ & $81(34.8)$ & $111(39.6)$ & $1.29(0.67-1.95)$ & & \\
\hline Ever & $\mathrm{TT}$ & $36(15.5)$ & $33(11.8)$ & $1.83(0.76-3.42)$ & & \\
\hline Ever & $\mathrm{TC}$ or $\mathrm{CC}$ & $74(31.8)$ & $68(24.3)$ & $1.58(0.93-2.39)$ & 0.52 & 0.76 \\
\hline $\mathrm{HBV} / \mathrm{HCV}$ infection & $r s 2278911$ & & & & & \\
\hline No & TT & $45(19.3)$ & $85(30.4)$ & Ref & & \\
\hline No & $\mathrm{TC}$ or $\mathrm{CC}$ & $70(30.0)$ & $164(58.6)$ & $0.69(0.35-1.58)$ & & \\
\hline Yes & TT & $33(14.2)$ & $16(5.7)$ & $4.36(1.94-8.62)$ & & \\
\hline Yes & $\mathrm{TC}$ or $\mathrm{CC}$ & $85(36.5)$ & $15(5.3)$ & $12.35(4.93-19.87)$ & 3.72 & 0.03 \\
\hline
\end{tabular}

${ }^{\mathrm{a} A d j u s t e d ~ f o r ~ a g e, ~ g e n d e r, ~ a l c o h o l ~ d r i n k i n g, ~ s m o k i n g ~ h i s t o r y, ~ H B s A g ~ o r ~ a n t i-H C V ~ a n d ~ f a m i l y ~ h i s t o r y . ~}{ }^{\mathrm{b}}$ Synergy index $(\mathrm{S})=\left(\mathrm{OR}_{11}-1\right) /$ $\left(\mathrm{OR}_{01}+\mathrm{OR}_{10}-2\right)$, in which $\mathrm{OR}_{11}=$ odds ratio of the joint effect of the two risk factors; $\mathrm{OR}_{01}$ and $\mathrm{OR}_{10}=$ odds ratio of each risk factor in the absence of the other.

controls. The CA, CG and TA haplotypes were not risk factors for HCC when using the haplotype and using TG as the reference $(\mathrm{CA}, \mathrm{P}=0.85$; $\mathrm{CG}, \mathrm{P}=0.95$; TA, $\mathrm{P}=0.80$ ).

The interactions of rs2278911 genotypes and other risk factors. Table IV shows the possible interactions between rs2278911 genotypes and other risk factors. An interaction between hepatitis infection (HBV and HCV) and the C carriers (TC or CC) of $r s 2278911$ was observed, with an $\mathrm{S}$ of $3.72(\mathrm{P}=0.03)$. Among the hepatitis virus infection ( $\mathrm{HBV}$ and $\mathrm{HCV}$ )-positive group, an increased risk of $\mathrm{HCC}$ was found with the presence of the C carriers (TC or CC) of $r s 2278911$ (OR=12.35; 95\% CI, 4.93-19.87). When evaluating the interactions of alcohol drinking and genotypes, we used non-drinkers with the TT genotype as the reference. No interaction between alcohol drinking and genotypes of $r s 2278911$ was observed, with an $\mathrm{S}$ of $1.74(\mathrm{P}=0.34)$. For smoking history, we used non-smokers with the TT genotype as the reference. No obvious interactions were found between the genotypes of $r s 2278911$ and tobacco consumption $(\mathrm{S}=0.52 ; \mathrm{P}=0.76)$.

The interactions of rs4855656 genotypes and other risk factors. Table $\mathrm{V}$ shows the possible interactions between rs 4855656 genotypes and other risk factors. No obvious interactions were observed between alcohol drinking, smoking history and hepatitis infection (HBV and HCV) and genotypes of $r s 4855656$. The $\mathrm{S}$ for interactions between smoking history and genotypes of $r s 4855656$, and hepatitis infection and genotypes of $r s 4855656$ were 3.40 and 1.66 , respectively. $\mathrm{P}>0.05$ in all cases.

\section{Discussion}

Two approaches have been commonly used to detect associations between HCC and common genetic variations. First, the hypothesis-directed approach is used to investigate func- 
Table V. Interactions between $r s 4855656$ genotypes and other risk factors.

\begin{tabular}{|c|c|c|c|c|c|c|}
\hline Risk factors & Genotype & $\begin{array}{l}\text { Cases } \\
\mathrm{N}(\%)\end{array}$ & $\begin{array}{l}\text { Controls } \\
\mathrm{N}(\%)\end{array}$ & OR $(95 \% \mathrm{CI})^{\mathrm{a}}$ & $\begin{array}{c}\text { Synergy } \\
\text { index }^{b}(S)\end{array}$ & P-value \\
\hline Alcohol drinking & $r s 4855656$ & & & & & \\
\hline Never & GG & $77(33.0)$ & $115(41.1)$ & Ref & & \\
\hline Never & GA or AA & $74(31.8)$ & $101(36.1)$ & $1.23(0.66-1.85)$ & & \\
\hline Ever & GG & $57(24.5)$ & $37(13.2)$ & $2.20(1.24-3.89)$ & & \\
\hline Ever & GA or AA & $25(10.7)$ & $27(9.6)$ & $1.53(0.89-2.96)$ & 0.37 & 0.12 \\
\hline Smoking history & $r s 4855656$ & & & & & \\
\hline Never & GG & $75(32.2)$ & $96(34.3)$ & Ref & & \\
\hline Never & GA or AA & $48(20.6)$ & $83(29.6)$ & $0.68(0.33-1.06)$ & & \\
\hline Ever & GG & $59(25.3)$ & $56(20)$ & $1.42(0.92-2.45)$ & & \\
\hline Ever & GA or AA & $51(21.9)$ & $45(16.1)$ & $1.34(0.65-2.27)$ & 3.40 & 0.41 \\
\hline $\mathrm{HBV} / \mathrm{HCV}$ infection & $r s 4855656$ & & & & & \\
\hline No & GG & $69(29.6)$ & $132(47.1)$ & Ref & & \\
\hline No & GA or AA & $46(19.7)$ & $117(41.8)$ & $0.75(0.48-1.18)$ & & \\
\hline Yes & GG & $65(27.9)$ & $20(7.1)$ & $6.23(3.48-11.12)$ & & \\
\hline Yes & GA or AA & $53(22.7)$ & $11(3.9)$ & $9.27(4.54-18.79)$ & 1.66 & 0.34 \\
\hline
\end{tabular}

tional SNPs in coding regions since they may dysregulate the expression of proteins (12-15). Second, the indirect approach is used to select a set of htSNPs which are informative polymorphisms that best characterize the haplotype diversity of a given chromosomal region. These htSNPs serve as markers to detect associations between a particular region and diseases, regardless of whether or not the SNPs themselves have a functional effect $(27,28)$. Previous studies have mostly used the hypothesis-directed approach to report associations between several variants and the risk of $\operatorname{HCC}(13,14)$. To the best of our knowledge, this is also the first study on CIP2A and HCC susceptibility by htSNP strategy. We performed a study of two htSNPs in a Chinese Han population and no obvious associations between the two individual htSNPs and the risk of HCC were found. With the present genotype distribution and at a significance level of 0.05 , the OR values of the TC genotype and $\mathrm{C}$ carriers of $r s 2278911$ and the AA genotype of $r s 4855656$ were all $>1$, but the $95 \%$ CI ranges all included 1 .

Haplotype analysis is more sensitive and powerful than single htSNP analysis. Additional etiological information was obtained by analyzing combinations of the two htSNPs. Four haplotypes were detected, TG, CA, CG and TA. However, none of the four haplotypes were found to be associated with the risk of HCC in our study.

Environmental risk factors and SNPs are regarded as major pathogenic factors in HCC development (29). Excessive alcohol consumption and hepatitis infection (HBV and HCV) are associated with $\mathrm{HCC}$, and has previously been evaluated $(30,31)$. An interaction was observed between $\mathrm{HBV} / \mathrm{HCV}$ infection and genotypes of $r s 2278911$ in this study. As a result, rs2278911 C carriers with HBV/HCV infection may exhibit increased susceptibility to HCC. However, no such association was found for $r s 4855656$. This finding indicated that the HBV/ $\mathrm{HCV}$ infection and SNPs may have a synergistic effect. The possible mechanism may be that $r s 2278911$ carries a $\mathrm{T}$ to $\mathrm{C}$ point mutation at the nucleotide position which converts the highly conserved 229 amino acid from Arginine to Glutamine, which may dysregulate the expression of CIP2A. Hepatitis infection may accelerate the process of this change and eventually trigger the occurrence and promote the development of HCC. The above-mentioned process may provide an explanation for the manner in which such environmental risk factors and the $r$ s2278911 polymorphism may have a combined effect on HCC. However, the exact mechanism underlying the development of HCC remains to be investigated.

Our study has certain limitations. One is that in the HapMap database, common CIP2A haplotypes were tagged by two SNPs. The one SNP per $20 \mathrm{~kb}$ density available for CIP2A in HapMap may therefore be insufficient for the identification of disease-predisposing variants. The other limitation of this study is the relatively small sample size, which may have prevented the adequate tagging of diseasepredisposing variants.

In conclusion, the present study suggests that genetic variation in the CIP2A gene alone is not associated with the risk of $\mathrm{HCC}$. However, HBV/HCV infection may enhance the risk of HCC in C carriers (TC or CC) of rs2278911 in the Chinese Han population. Further studies using a larger sample size are required for validation. 


\section{Acknowledgements}

This study was supported by grants from the National Natural Science Foundation of China (Nos. 30872962 and 81172086). We thank all the participants who contributed to this study, and all the collaborators who conducted the collection of samples and clinical information.

\section{References}

1. El-Serag HB and Rudolph KL: Hepatocellular carcinoma: Epidemiology and molecular carcinogenesis. Gastroenterology 1329: 2557-2576, 2007.

2. Asia-Pacific Working Party on Prevention of Hepatocellular Carcinoma: Prevention of hepatocellular carcinoma in the AsiaPacific region: consensus statements. J Gastroenterol Hepatol 25 657-663, 2010.

3. International Agency for Research on Cancer: GLOBOCAN 2008. Geneva: WHO. Available at http://www-dep.iarc.fr/.

4. Mori M, Hara M, Wada I, Hara I, Yamamoto K, Honda M and Naramoto J: Prospective study of hepatitis B and C viral infections, cigarette smoking, alcohol consumption, and other factors associated with hepatocellular carcinoma risk in Japan. Am J Epidemiol 151: 131-139, 2000.

5. Yuan JM, Govindarajan S, Arakawa K and Yu MC: Synergism of alcohol, diabetes, and viral hepatitis on the risk of hepatocellular carcinoma in blacks and whites in the U.S. Cancer 101: 1009-1017, 2004.

6. Jee SH, Ohrr H, Sull JW and Samet JM: Cigarette smoking, alcohol drinking, hepatitis B, and risk for hepatocellular carcinoma in Korea. J Natl Cancer Inst 96: 1851-1856, 2004.

7. Kuper H, Tzonou A, Kaklamani E, et al: Tobacco smoking, alcohol consumption and their interaction in the causation of hepatocellular carcinoma. Int J Cancer 85: 498-502, 2000.

8. Marrero JA, Fontana RJ, Fu S, Conjeevaram HS, Su GL and Lok AS: Alcohol, tobacco and obesity are synergistic risk factors for hepatocellular carcinoma. J Hepatol 42: 218-224, 2005

9. Zhang JY, Dai M, Wang X, et al: A case-control study of hepatitis $\mathrm{B}$ and $\mathrm{C}$ virus infection as risk factors for hepatocellular carcinoma in Henan, China. Int J Epidemiol 27: 574-578, 1998.

10. Zhang JY, Wang X, Han SG and Zhuang H: A case-control study of risk factors for hepatocellular carcinoma in Henan, China. Am J Trop Med Hyg 59: 947-951, 1998.

11. Budhu A and Wang XW: The role of cytokines in hepatocellular carcinoma. J Leukoc Biol 80: 1197-1213, 2006.

12. Giacalone A, Montalto G, Giannitrapani L, et al: Association between single nucleotide polymorphisms in the cyclooxygenase-2, tumor necrosis factor- $\alpha$, and vascular endothelial growth factor-A genes, and susceptibility to hepatocellular carcinoma. OMICS 15: 193-196, 2011.

13. Li S, Deng Y, Chen ZP, et al: Genetic polymorphism of interleukin-16 influences susceptibility to HBV-related hepatocellular carcinoma in a Chinese population. Infect Genet Evol 11: 2083-2088, 2011.
14. Chinen MH, Yeh CB, Li YC, et al: Relationship of interleukin-8 gene polymorphisms with hepatocellular carcinoma susceptibility and pathological development. J Surg Oncol 104: 798-803, 2011.

15. Sümbül AT, Akkiz H, Bayram S, Bekar A, Akqöllü E and Sandikçı M: p53 codon 72 polymorphism is associated with susceptibility to hepatocellular carcinoma in the Turkish population: a case-control study. Mol Biol Rep 39: 1639-1647, 2012.

16. Chakravarti A: Population genetics - making sense out of sequence. Nat Genet 21: 56-60, 1999.

17. Ikeda M, Iwata N, Kitajima T, Suzuki T, Yamanouchi Y, Kinoshita Y and Ozaki N: Positive association of the serotonin 5-HT7 receptor gene with schizophrenia in a Japanese population. Neuropsychopharmacology 31: 866-871, 2006.

18. The International HapMap Consortium: A haplotype map of the human genome. Nature 437: 1299-1320, 2005.

19. International HapMap Consortium, Frazer KA, Ballinqer DG, et al: A second generation human haplotype map of over 3.1 million SNPs. Nature 449: 851-861, 2007.

20. de Bakker PI, Burtt NP, Graham RR, et al: Transferability of tag SNPs in genetic association studies in multiple populations. Nat Genet 38: 1298-1303, 2006.

21. Soo Hoo L, Zhang JY and Chan EK: Cloning and characterization of a novel $90 \mathrm{kDa}$ 'companion' auto-antigen of p62 overexpressed in cancer. Oncogene 21: 5006-5015, 2002.

22. Zhang JY, Wang X, Peng XX and Chan EK: Autoantibody responses in Chinese hepatocellular carcinoma. J Clin Immunol 22: 98-105, 2002.

23. Junttila MR, Puustinen $\mathrm{P}$, Niemelä $\mathrm{M}$, et al: CIP2A inhibits PP2A in human malignancies. Cell 130: 51-62, 2007.

24. Ye S, Dhillon S, Ke X, Collins AR and Dav IN: An efficient procedure for genotyping single nucleotide polymorphisms. Nucleic Acids Res 29: E88-8, 2001.

25. Little S: Amplification-refractory mutation system (ARMS) analysis of point mutations. Curr Protoc Hum Genet Chapter 9: Unit 9.8, 2001.

26. Rothman KJ: The estimation of synergy or antagonism. Am J Epidemiol 103: 506-511, 1976.

27. Han W, Kang D, Lee JE, et al: A haplotype analysis of HER-2 gene polymorphisms: association with breast cancer risk, HER-2 protein expression in the tumor, and disease recurrence in Korea. Clin Cancer Res 11: 4775-4778, 2005.

28. Hu Z, Xu L, Shao M, et al: Polymorphisms in the two helicases ERCC2/XPD and ERCC3/XPB of the transcription factor IIH complex and risk of lung cancer: a case-control analysis in a Chinese population. Cancer Epidemiol Biomarkers Prev 15: 1336-1340, 2006

29. Kirk GD, Bah E and Montesano R: Molecular epidemiology of human liver cancer: insights into etiology, pathogenesis and prevention from The Gambia, West Africa. Carcinogenesis 27: 2070-2082, 2006.

30. Brechot C, Kremsdorf D, Soussan P, Pineau P, Dejean A, Paterlini-Brechot $\mathrm{P}$ and Tiollais P: Hepatitis B virus (HBV)related hepatocellular carcinoma (HCC): molecular mechanisms and novel paradigms. Pathol Biol (Paris) 58: 278-287, 2010.

31. Koike K: Hepatitis C virus contributes to hepatocarcinogenesis by modulating metabolic and intracellular signaling pathways. J Gastroenterol Hepatol 22: S108-S111, 2007. 